\title{
Toxoplasma gondii infection: seroprevalence and associated risk factors among primary schoolchildren in Lagos City, Southern Nigeria
}

\author{
Vincent Pam Gyang ${ }^{[1],[2],[3]}$, Olaoluwa Pheabian Akinwale ${ }^{[3]}$, Yueh-Lun Lee ${ }^{[4]}$, \\ Ting-Wu Chuang ${ }^{[2]}$, Akwaowo Orok ${ }^{[5]}$, Olusola Ajibaye ${ }^{[5]}$, Chien-Wei Liao ${ }^{[2]}$, \\ Po-Ching Cheng ${ }^{[2]}$, Chia-Mei Chou ${ }^{[2]}$, Ying-Chieh Huang ${ }^{[2]}$, Kuo-Hua Fan ${ }^{[6],[7]}$ \\ and Chia-Kwung Fan ${ }^{[1],[2],[8]}$
}

\begin{abstract}
[1]. Graduate Institute of Medical Sciences, College of Medicine, Taipei Medical University, Taipei, Taiwan. [2]. Department of Molecular Parasitology and Tropical Diseases, School of Medicine, College of Medicine, Taipei Medical University, Taipei, Taiwan. [3]. Public Health Division, Molecular Parasitology Research Laboratory, Nigerian Institute of Medical Research, Yaba, Lagos State, Nigeria. [4]. Department of Microbiology and Immunology, School of Medicine, College of Medicine, Taipei Medical University, Taipei, Taiwan. [5]. Biochemistry and Nutrition Division, Nigerian Institute of Medical Research, Yaba, Lagos State, Nigeria. [6].Owner \& Patent Attorney Zoomlaw IP Attorneys, Hsinchu County, Taiwan. [7]. Intellectual Property Law Institute, Shih-Hsin University, Taipei, Taiwan. [8]. Master Program in Global Health and Development, College of Public Health and Nutrition, Taipei Medical University, Taipei, Taiwan.
\end{abstract}

\begin{abstract}
Introduction: Toxoplasma gondii infection has been described as the most widespread zoonotic infection of humans and other animals. Information concerning T. gondii infection among schoolchildren is unavailable in Lagos City, Nigeria. Methods: This crosssectional study investigated the seroprevalence and risk factors associated with $T$. gondii infection among primary schoolchildren (PSC) from a community located in the center of Lagos, southern Nigeria, from November 2013 to March 2014. A total of 382 PSC were screened for the presence of sera anti-T. gondii antibodies using a latex agglutination test (TOXO Test-MT, Tokyo, Japan). A cutoff titer of $\geq 1: 32$ was considered positive, while titers $\geq 1: 1,024$ indicated high responders. Questionnaires were also used to obtain data on possible risk factors from parents/guardians. Results: The overall seroprevalence was 24\% (91/382), and 83.5\% (76/91) of seropositive PSC were classified as high responders. Among the risk factors tested, including contact with cats and soil, consumption of raw meat and vegetables, and drinking unboiled water, none showed statistical significance after multivariate adjustment. No associations were observed among age, gender, body mass index (BMI), and parents' occupation/educational level. Conclusions: The findings in this study show evidence of active infection, and hence, there is need for urgent preventive measures in this city. Further investigation is required to clarify the transmission routes. Policy makers also need to initiate prevention and control programs to protect pregnant women and immunocompromised patients in particular because they are more severely affected by $T$. gondii infection.
\end{abstract}

Keywords: Toxoplasma gondii. Latex agglutination test. Primary schoolchildren. Risk factors. Nigeria.

\section{INTRODUCTION}

Toxoplasma gondii is an intracellular protozoan parasite with a widespread distribution. T. gondii has a large variety of hosts, including humans and most warm-blooded species, but it completes its sexual cycle and produces oocysts only in the intestinal tracts of felids ${ }^{(1)}$. Worldwide, over 6 billion people have been infected with $T$. gondii( ${ }^{(2)}$. Although it is a cosmopolitan infection, the disease appears to be overshadowed in the tropics, especially in Sub-Saharan Africa (SSA), by other

\footnotetext{
Address to: Dr. Chia-Kwung Fan. Department of Molecular Parasitology and Tropical Diseases/School of Medicine/College of Medicine/Taipei Medical University. $250 \mathrm{Wu}-$ Xing Street, Taipei 11001, Taiwan.

Phone/Fax: 8862 2739-5092

e-mail: tedfan@tmu.edu.tw

Received 13 December 2014

Accepted 3 March 2015
}

endemic diseases such as malaria and human immunodeficiency virus $(\mathrm{HIV})^{(3)}$.

Humans acquire $T$. gondii infection through oral ingestion of food or water contaminated with oocysts from cat feces, ingestion of cysts contained in raw or undercooked meat, transplacental transmission of tachyzoites from the infected mother to her fetus, and tachyzoites and tissue cyst acquisition via solid organ transplantation ${ }^{(1)}{ }^{(4)}$. Post infection, adults and children with normal immune function remain asymptomatic or develop only mild symptoms, such as fever and malaise, although up to $10 \%$ will present with cervical lymphadenopathy or ocular disease ${ }^{(1)}$. Of note, substantial evidence indicates that $T$. gondii has emerged as an interesting candidate as a possible cause of some cases of schizophrenia ${ }^{(5)}$.

Although the clinical presentation of toxoplasmosis is benign in an immunocompetent population, in immunocompromised persons, such as HIV patients, toxoplasmosis is the most frequent severe neurologic infection. Toxoplasmic encephalitis (TE) 
due to reactivation of a latent infection may lead to severe cerebral lesions in acquired immunodeficiency syndrome (AIDS) patients ${ }^{(6)(7)}$. Children and young adults can also suffer from toxoplasmic chorioretinitis, which is a common late manifestation of congenital infection or acute infection ${ }^{(1)}$. In pregnant women, when infection is transmitted to the fetus, it may lead to mental retardation, blindness, epilepsy and death ${ }^{(1)}$. The severity of the outcomes for newborns depends on the gestational stage during pregnancy when the infection occurred; early maternal infection (in the first trimester) can cause more significant congenital toxoplasmosis in newborns ${ }^{(1)(8)}$. T. gondii is a member of the TORCH group of infections (which includes rubella, cytomegalovirus, and herpes viruses) that can cause congenital abnormalities and even death in fetuses ${ }^{(1)(9)}$.

The detection of the T. gondii parasite itself is very difficult; hence, the diagnosis of human toxoplasmosis is typically based on serological detection of antibodies against $T$. gondii using latex agglutination (LA) testing, enzyme-linked immunosorbent assay (ELISA), and/or indirect fluorescent antibody testing (IFAT). Latex agglutination testing is better adapted for developing countries where rural districts often lack the equipment needed for ELISA ${ }^{(10)(11)(12)}$. Moreover, LA is also simpler and easier to perform, and it shows high qualitative agreement with the Sabin-Feldman dye test, which represents the gold standard ${ }^{(13)}$.

Seroprevalence rates of $T$. gondii have been shown to vary from $0 \%$ in Eskimos ${ }^{(14)}$ to $93 \%$ in Ghanaians ${ }^{(15)}$. In recent studies, these rates have been reported to be $70 \%$ in Indonesia, $81 \%$ in Ethiopia, $52 \%$ in Brazil, $10.8 \%$ in the U.S., and $13.2 \%$ in Korea $^{(16)(17)(18)(19)(20)}$. Although these studies targeted different populations and used different immunological assays, the widespread prevalence of this infection is indisputable.

In Africa, the majority of surveys have been carried out on immunocompetent adults, followed by women of reproductive age and then on HIV/AIDS patients ${ }^{(21)}$; however, studies concerning the seroprevalence of $T$. gondii in primary schoolchildren (PSC) are limited ${ }^{(22)}$. Furthermore, few studies have been performed in countries such as Somalia, East Africa, Madagascar and Swaziland ${ }^{(12)(23)(24)}$. In Nigeria, information on the seroprevalence of $T$. gondii among PSC is unavailable.

Toxoplasmosis has been described as an environmental disease because transmission has been shown to be promoted by poor environmental sanitation, overcrowding, poverty, certain eating habits and poor hygiene ${ }^{(25)(26)}$.

This cross-sectional study was therefore designed to investigate the seroprevalence and risk factors associated with T. gondii infection in PSC, with the aim of understanding the fundamental epidemiology and environmental risks of $T$. gondii infection in Lagos City, Nigeria, which is the largest city in SSA.

\section{METHODS}

Primary schools located in a community of the Mainland Local Government Area (LGA), which is located within the center of Lagos City, Southern Nigeria, were selected. These schools lie within latitude $6^{\circ} 28^{\prime}$ and $6^{\circ} 29^{\prime}$ and longitude $3^{\circ} 12^{\prime}$ and $3^{\circ} 13^{\prime}$. This community has an estimated population of approximately 100,000 inhabitants and is located partly on land and partly on the Lagos lagoon. The major occupation is fishing and trading, especially among individuals living on the lagoon. This community suffers from serious environmental and infrastructural deficiencies, including inadequate access roads, schools, health care facilities and housing; however, many foods that are consumed daily, such as vegetables and fishes, are transported from this community to various areas within Lagos $^{(27)}$. This cross-sectional study was carried out between November 2013 and March 2014 and was conducted in the only three government-built primary schools, namely Adekunle Anglican Church Primary School, Ayetoro African Church Primary School and Makoko Anglican Church Primary School.

Schoolchildren attending these three government-built primary schools were involved in the study. A medical laboratory scientist collected blood specimens after verifying the informed consent forms from the pupils. Attached to the consent forms were structured questionnaires designed to capture basic demographic data regarding age, gender, parental educational level and occupation. Height and weight were recorded by the health workers using standard calibrated instruments. The children were divided into three age groups to maintain a sufficient sample size in the analysis: Group 1, < 10 years; Group 2, 10-12 years; and Group 3, > 12 years. Parental occupation was also categorized into three groups: Group 1, unemployed; Group 2, unskilled workers; and Group 3, skilled workers.

Different risk factors in the environment were also investigated in the study, including contact with cats, cat feeding practices, contact with soil, drinking unsafe water, eating raw (unwashed) vegetables, and consuming raw or undercooked meat, and were used in the multivariate analysis. Approximately $3-5 \mathrm{ml}$ of blood was drawn from each child by venipuncture, and the sera were collected and then stored at $-20^{\circ} \mathrm{C}$ until use. All of the sera were screened for anti-T. gondii antibodies using a commercial test kit based on LA (TOXO Test-MT, Eiken Co. Ltd, Tokyo, Japan), according to manufacturer's instructions. A cutoff titer of 1:32 or higher was considered positive, while titers equal to or greater than 1:1,024 indicated high responders ${ }^{(22)(28)}$.

Evaluation of the associations between demographic characteristics and $T$. gondii infection was performed by a chi-squared test to compare the proportions of infection based on gender, age group, body mass index (BMI), and parental occupation and educational level. The log-binomial regression model was applied to investigate multiple environmental risk factors associated with $T$. gondii infection. The prevalence ratio, which is considered a less biased indicator than the odds ratio, was generated from the log-binomial models. All of the statistical analyses were conducted using SAS Version 9.3 (SAS Institute, Inc., Cary, NC, USA). The $\alpha$-level was set at 0.05 , and a $p$ value less than 0.05 was regarded as statistically significant.

\section{Ethical considerations}

Prior to commencement of the study, permission was obtained from the local education authority of the Local Government Area (Mainland LGA). Approval was also obtained 
from the head teachers of each of the selected schools and from parents or guardians of the children. Meetings were held to explain to the teachers and pupils the objectives and protocol of the study, emphasizing that participation was voluntary and that withdrawal was allowed without any reason required. Signed or thumb-printed consent was obtained from parents/guardians on behalf of their children/wards before the commencement of sample collection. The guidelines laid down for procedures involving human subjects in the Declaration of Helsinki were strictly adhered to, and approval for this study was granted by the Institutional Review Board (IRB) of the Nigerian Institute of Medical Research (NIMR) [Project No.: IRB/13/225].

\section{RESULTS}

In total, 382 schoolchildren were enrolled in the present study, of which 195 were females and 187 were males, with an average age of 10.8 years. As shown in Table 1, the overall seroprevalence of $T$. gondii was $24 \%$ (91/382), while the highresponder rate was $20 \%(76 / 382)$. There was an increasing pattern of infection and high-responder status with increasing age, although this trend was not statistically significant. No significant associations were found between infection and gender, BMI, or parents' occupation/educational level
(Table 1). There was high awareness of cats serving as reservoirs of some diseases $(80.7 \%)$, but little was known about $T$. gondii (35\%), as shown in Table 2. Among the symptoms presented, children with general body weakness showed higher infection rates compared with their non-weak counterparts, while headache and ocular discomfort showed no such relationships (Table 2). Table 3 shows the results of the multivariate analysis. Overall, no statistically significant risk factors were identified in the models. On univariate analysis, raw meat consumption showed higher risk [adjusted prevalence ratio $(\mathrm{APR})=1.31$ ] and contact with soil showed lower risk $(\mathrm{APR}=0.66)$ for $T$. gondii infection. Socioeconomic and demographic factors did not show a significant association with $T$. gondii infection, including gender, age, BMI, or parental occupation/educational level. None of these factors was significant after the univariate and multivariate analyses in this study (Table 3).

\section{DISCUSSION}

The LA test employed in the present study has shown $96.3 \%$ sensitivity and $97.1 \%$ specificity ${ }^{(29)}$ and ease-of-use in realworld contexts; it also has a high qualitative agreement with the Sabin-Feldman dye test, which represents the gold standard ${ }^{(13)}$. Moreover, the LA test has been widely used in remote or rural areas in many developing countries ${ }^{(12)(22)(30)}$.

TABLE 1 - Demographic characteristics and infection rates of Toxoplasma gondii among primary schoolchildren in Lagos City, Southern Nigeria.

\begin{tabular}{|c|c|c|c|c|}
\hline \multirow[b]{2}{*}{ Variables } & \multicolumn{2}{|c|}{ Infection rate } & \multicolumn{2}{|c|}{ Infection rate $($ Titer $>1024)$} \\
\hline & $\mathrm{n}$ & $\%$ & $\mathrm{n}$ & $\%$ \\
\hline \multicolumn{5}{|l|}{ Gender } \\
\hline female $(n=195)$ & 42 & 21.54 & 34 & 17.4 \\
\hline male $(n=187)$ & 49 & 26.34 & 42 & 22.46 \\
\hline $10-12(n=226)$ & 52 & 23.01 & 44 & 19.38 \\
\hline$>12(\mathrm{n}=67)$ & 19 & 28.36 & 15 & 22.39 \\
\hline \multicolumn{5}{|l|}{ Body mass index } \\
\hline unemployed $(\mathrm{n}=182)$ & 45 & 24.73 & 36 & 19.78 \\
\hline unskilled worker $(\mathrm{n}=155)$ & 31 & 20.00 & 26 & 16.67 \\
\hline skilled worker $(\mathrm{n}=46)$ & 15 & 32.61 & 14 & 30.43 \\
\hline \multicolumn{5}{|l|}{ Parent's education } \\
\hline primary School (n=248) & 65 & 26.21 & 54 & 21.69 \\
\hline high School (n=103) & 18 & 19.78 & 14 & 13.59 \\
\hline college $(n=32)$ & 8 & 25.00 & 8 & 25.00 \\
\hline
\end{tabular}


TABLE 2 - Knowledge of Toxoplasma gondii infection and general symptoms in primary children in Lagos City, Southern Nigeria.

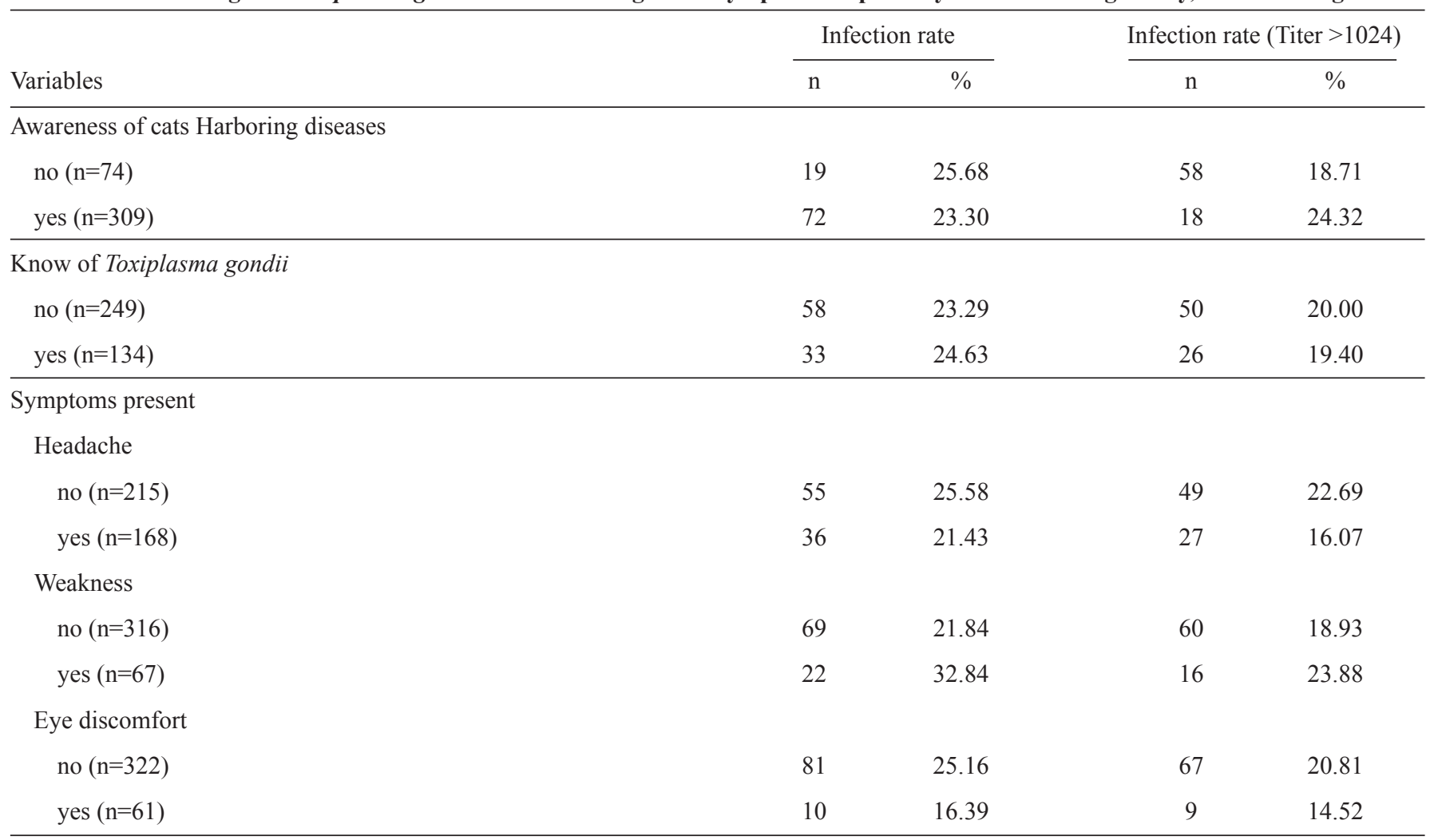

TABLE 3 - Log-binomial regression model analysis of Toxoplasma gondii infection and associated risk factors among primary children in Lagos City, Southern Nigeria.

\begin{tabular}{|c|c|c|c|c|}
\hline Variables & \multicolumn{2}{|c|}{ Univariate analysis } & \multicolumn{2}{|c|}{ Multivariate analysis } \\
\hline \multicolumn{5}{|l|}{ Gender } \\
\hline male $(\mathrm{n}=187)$ & 1.00 & 1.00 & & \\
\hline female $(\mathrm{n}=195)$ & 0.82 & $0.57-1.17$ & 0.80 & $0.51-1.22$ \\
\hline$<10(\mathrm{n}=90)$ & 1.00 & 1.00 & & \\
\hline $10-12(n=226)$ & 1.04 & $0.67-1.68$ & 0.96 & $0.74-1.76$ \\
\hline$>12(\mathrm{n}=67)$ & 1.28 & $0.73-2.21$ & 1.21 & $0.88-2.46$ \\
\hline \multicolumn{5}{|l|}{ Parent's occupation } \\
\hline \multicolumn{5}{|l|}{ Body mass index } \\
\hline normal (n =337) & 1.00 & 1.00 & & \\
\hline underweight $(\mathrm{n}=46)$ & 1.33 & $0.78-2.06$ & 1.20 & $0.65-1.67$ \\
\hline
\end{tabular}


TABLE 3 - Continuation.

\begin{tabular}{|c|c|c|c|c|}
\hline \multirow[b]{2}{*}{ Variables } & \multicolumn{2}{|c|}{ Univariate analysis } & \multicolumn{2}{|c|}{ Multivariate analysis } \\
\hline & CPR & $95 \% \mathrm{CI}$ & APR & $95 \% \mathrm{CI}$ \\
\hline \multicolumn{5}{|l|}{ Parent's education } \\
\hline primary school $(\mathrm{n}=248)$ & 1.00 & 1.00 & & \\
\hline high school $(\mathrm{n}=103)$ & 0.67 & $0.40-1.04$ & 0.62 & $0.37-1.04$ \\
\hline college $(n=32)$ & 0.95 & $0.46-1.67$ & 0.95 & $0.55-1.80$ \\
\hline \multicolumn{5}{|l|}{ Contact with cats } \\
\hline no $(\mathrm{n}=221)$ & 1.00 & 1.00 & & \\
\hline yes $(n=162)$ & 1.02 & $0.71-1.47$ & 0.87 & $0.39-2.36$ \\
\hline \multicolumn{5}{|l|}{ Age of the cats } \\
\hline ref & 1.00 & 1.00 & & \\
\hline young $(\mathrm{n}=63)$ & 0.89 & $0.51-1.42$ & 0.75 & $0.21-1.49$ \\
\hline adult $(\mathrm{n}=39)$ & 0.72 & $0.32-1.33$ & 0.58 & $0.87-4.73$ \\
\hline \multicolumn{5}{|l|}{ Feeding location } \\
\hline ref & 1.00 & 1.00 & & \\
\hline inside $(n=48)$ & 1.28 & $0.76-2.00$ & 1.09 & $0.87-4.74$ \\
\hline outside $(\mathrm{n}=109)$ & 0.79 & $0.49-1.22$ & 0.56 & $0.45-2.53$ \\
\hline \multicolumn{5}{|l|}{ Cleaning frequency } \\
\hline ref & 1.00 & 1.00 & & \\
\hline never $(\mathrm{n}=25)$ & 1.20 & $0.55-2.16$ & 2.13 & $0.33-5.45$ \\
\hline regular $(\mathrm{n}=135)$ & 1.02 & $0.68-1.48$ & 1.74 & $0.33-6.49$ \\
\hline \multicolumn{5}{|l|}{ Clean cat hutch with gloves } \\
\hline ref & 1.00 & 1.00 & & \\
\hline no $(\mathrm{n}=44)$ & 0.86 & $0.42-1.52$ & 0.90 & $0.15-1.88$ \\
\hline yes $(n=111)$ & 1.07 & $0.70-1.57$ & 1.20 & $0.26-2.33$ \\
\hline \multicolumn{5}{|l|}{ Consume raw vegetables } \\
\hline no $(\mathrm{n}=221)$ & 1.00 & 1.00 & & \\
\hline yes $(n=162)$ & 0.92 & $0.61-1.34$ & 0.94 & $0.72-1.55$ \\
\hline \multicolumn{5}{|l|}{ Touch soil } \\
\hline no $(\mathrm{n}=161)$ & 1.00 & 1.00 & & \\
\hline yes $(n=222)$ & 0.71 & $0.49-1.02$ & 0.66 & $0.51-1.08$ \\
\hline \multicolumn{5}{|l|}{ Consume uncooked meat } \\
\hline no $(\mathrm{n}=108)$ & 1.00 & 1.00 & & \\
\hline yes $(n=275)$ & 1.09 & $0.74-1.69$ & 1.31 & $0.84-2.46$ \\
\hline \multicolumn{5}{|l|}{ Drink unboiled water } \\
\hline no $(\mathrm{n}=195)$ & 1.00 & 1.00 & & \\
\hline yes $(n=188)$ & 0.93 & $0.65-1.33$ & 0.95 & $0.60-1.60$ \\
\hline
\end{tabular}

CPR: crude prevalence ratio; APR: adjusted prevalence ratio; 95\% CI: 95\% confidence interval. 
The community studied is located within the heart of Lagos City, the largest city in Nigeria, and its climatic and living conditions favor many parasites. PSC are a highly vulnerable population for $T$. gondii infection due to their habits of playing in water, soil, with pets (cats and dogs), and eating raw and unwashed foods ${ }^{(22)}$. This age group also lacks good personal hygiene. The results obtained from this study can be used to assess whether T. gondii threatens the well-being of these children, and they can also be used as a reference in determining the need to plan primary prevention actions for pregnant women and people with immunosuppression. Intervention in adjacent areas in Lagos may also be required because many of the foods consumed daily, such as vegetables and fishes, are transported from this community to various districts in Lagos ${ }^{(27)(31)}$.

The results from this study showed that $24 \%$ of PSC were infected with $T$. gondii. This seroprevalence was lower than previous prevalence values recorded in Brazil ${ }^{(32)}(46.4 \%)$, São Tome and Principe ${ }^{(22)}$ (63.1\%), Somalia ${ }^{(24)}$ (37.5\%), and Madagascar ${ }^{(23)}(36.3 \%)$, although it was higher than the prevalence values reported in Swaziland ${ }^{(12)}(8 \%)$ and China ${ }^{(33)}$ $(15.13 \%)$. Variations in prevalence may also occur between regions of the same country, such as the prevalence values of $17.5 \%{ }^{(34)}$ and $46.4 \%{ }^{(32)}$ that have both been reported in Brazil. These differences could be attributable to variations in culture and tradition among different ethnicities as well as different food habits ${ }^{(22)(28)(35)}$.

Previous studies have indicated that the parent's occupation is a factor that influences the likelihood that a PSC will be infected with $T$. gondii ${ }^{(22)(28)(36)}$. Generally, children whose parents' occupations are categorized as unskilled workers tend to be infected more frequently, which could be due to the parents' lacks of sufficient knowledge of personal hygiene. However, in this study, there was no significant association between parents' occupation/educational level and infection. An alternative explanation may be that people acquire $T$. gondii infection through contaminated environments in the community, regardless of their occupation/educational level. In this study, no gender difference was found associated with the seroprevalence of T. gondii, supporting observations made elsewhere ${ }^{(34)(35)(37)}$.

High LA titers of sera anti-Toxoplasma antibodies are regarded as an indicator of either acute or new infection with T. gondii $^{(38)}$. In present study, among seropositive PSC, $86 \%$ (42/49) of boys and $81 \%(34 / 42)$ of girls showed high LA titers. This result indicates that many of the children in this community were recently infected with $T$. gondii, which could have occurred through risk factors such as playing in soil, playing with pets (cats and dogs), eating raw and unwashed foods, eating raw/ undercooked meat or drinking of unsafe water ${ }^{(4)}$.

Substantial studies have indicated that the seroprevalence of T. gondii infection increases with age ${ }^{(10)(39)}$, and one hypothesis suggests that this outcome is the result of an increasing number of exposure years as the child grows ${ }^{(40)}$. There was an increasing pattern of infection rates with age in this study as well, but the trend was not statistically significant, which may have been due to the small sample numbers in some age groups making it difficult to demonstrate a difference.
Among the risk factors analyzed in this study, playing/ contact with soil showed lower risk $(\mathrm{APR}=0.66)$ after the multivariate adjustment to evaluate for associations between multiple environmental risk factors and $T$. gondii infection. This route of transmission could explain the similar incidence of seropositivity between boys and girls in this community because both genders are equally exposed to contact with soil. This infection route corroborates the findings of previous studies in urban Brazil ${ }^{(41)}$.

Contact with domestic cats is one of the generally accepted risk factors for infection with toxoplasmosis ${ }^{(1)}$, although no association was observed in this study, in agreement with previous studies $^{(3)(22)(28)(38)}$. The way a cat's litter box is cleaned seems to account for exposure to the parasite rather than the mere presence of cats in the household; in our study, most cat owners used gloves while cleaning the litter box. The lack of an association between cat ownership and infection could also suggest that environmental contamination by cats is so widespread that cat ownership has minimal effects on the level of exposure to T. gondii( ${ }^{(39)}$.

Drinking contaminated water is also a potential source of T. gondii infection ${ }^{(3)}$. A study in Nigeria showed that the seroprevalence rate was higher in pregnant women who drank well water compared with women using packaged water ${ }^{(42)}$. However, in our study, $49.1 \%$ of the children reported the use of unsafe water, and no association between the source of drinking water and Toxoplasma infection was found. Nevertheless, waterborne outbreaks of toxoplasmosis have been reported in Brazil $^{(43)}$. The consumption of raw meat also did not seem to be a significant risk factor in this community because meat is traditionally well cooked. However, eating raw and unwashed vegetables can serve as a route of infection, although it was not statistically significant in this study.

Substantial evidence has established an association between T. gondii infection and headaches ${ }^{(44)}$; however, in our study, no association was observed. Ocular disease has also been reported to be linked with $T$. gondii infection, particularly in the U.S. ${ }^{(45)}$. In our study, visual discomfort showed no association with infection. This lack of an association might be due to an insufficient sample size; hence, there is a need for further large-scale investigations to answer this question. Of note, our study showed an association between $T$. gondii infection and general body weakness, although the association was not statistically significant. This weakness could also be due to the other pathogenic infections that are prevalent in Nigeria ${ }^{(46)}$; therefore, more investigation is required in this area. Given the moderate seroprevalence recorded in present study, there is a need for preventive measures against $T$. gondii in Lagos, Nigeria. Although infection is generally asymptomatic in affected children, in some regions, more aggressive disease strains lead to eye damage. The prevalence recorded in this study is an indication of the potential risks that pregnant women and immunocompromised patients are exposed to. Because general environmental contamination control is very difficult to achieve, strategies should be focused on these two sub-populations that are at higher risk of severe disease. Preventing contamination 
by cat feces, particularly in children's playgrounds, and good personal hygiene, such as regular hand washing, are essential steps in the control of $T$. gondii infection. Our results may also be of use to policy makers for the initiation of programs that can lead to the prevention and control of toxoplasmosis in Lagos specifically and in Nigeria as a whole.

\section{ACKNOWLEDGMENTS}

We would like to acknowledge the staff of the Nigerian Institute of Medical Research (NIMR), particularly the Public Health Division and the Molecular Parasitology Laboratory, as well as the staff of the Molecular Parasitology Department of Taipei Medical University (TMU) in Taiwan. We thank the local education authority, Mainland LGA of Lagos state and the head teachers and staff of the three schools used for the study. We are grateful to the community head for his immense assistance. Last, we sincerely want to thank the parents/guardians and their children for their participation in this study.

\section{CONFLICT OF INTEREST}

The authors declare that there is no conflict of interest.

\section{REFERENCES}

1. Montoya JG, Liesenfeld O. Toxoplasmosis. Lancet 2004; 363 : 1965-1976.

2. Furtado JM, Smith JR, Belfort R, Gattey D, Winthrop KL. Toxoplasmosis: a global threat. J Global Infect Dis 2011; 3: 281-284.

3. Fan CK, Liao CW, Kao TC, Lu JL, Su KE. Toxoplasma gondii infection: relationship between seroprevalence and risk factors among inhabitants in two offshore islands from Taiwan. Acta Med Okayama 2001; 55:301-308.

4. Alvarados-Esquivel C, Estrada-Martinez S, Liesenfeld O. Toxoplasma gondii infection in workers occupationally exposed to unwashed raw fruits and vegetables: a case control seroprevalence study. Parasit Vectors 2011; 4:235.

5. Torrey EF, Bartko JJ, Yolken RH. Toxoplasma gondii and other risk factors for schizophrenia: an update. Schizophr Bull 2012; 38:642-647.

6. Porter SB, Sande MA. Toxoplasmosis of the central nervous system in the acquired immunodeficiency syndrome. New Eng J Med 1992; 327:1643-1648.

7. Assis AM, Barreto ML, Gomes GS, Prado MS, Santos NS, Santos LM, et al. Childhood anemia prevalence and associated factors in Salvador, Bahia, Brazil. Cad Saude Publica 2004; 20:1633-1641.

8. Paquet C, Yudin MH. Toxoplasmosis in pregnancy: prevention, screening, and treatment. J Obstet Gynaecol 2013; 35:78-81.

9. Singh S. Mother-to-child transmission and diagnosis of Toxoplasma gondii infection during pregnancy. Indian J Med Microbiol 2003; 21:69-76.

10. Fan CK, Liao CW, Wu MS, Su KE, Han BC. Seroepidemiology of Toxoplasma gondii infection among Chinese aboriginal and Han people residing in mountainous areas of northern Thailand. J Parasitol 2003; 89:1239-1242.
11. Fu CJ, Chuang TW, Lin HS, Wu CH, Liu YC, Langinlur MK, et al. Toxoplasma gondii infection: seroprevalence and associated risk factors among primary school children in the capital area of the Republic of the Marshall Islands. Jpn J Infect Dis 2014; 67:405-410.

12. Liao CW, Lee YL, Sukati H, D'lamini P, Huang YC, Chiu CJ, et al. Seroprevalence of Toxoplasma gondii infection among children in Swaziland, South Africa. Ann Trop Med Parasitol 2009; 103: 731-736.

13. Balfour AH, Fleck DG, Hughes HP, Sharp D. Comparative study of three tests (dye test, indirect haemagglutination test, latex agglutination test) for the detection of antibodies to Toxoplasma gondii in human sera. J Clin Pathol 1982; 35: 228-232.

14. Gibson GL, Coleman N. The prevalence of Toxoplasma antibodies in Guatamala and Costa Rica. Am J Trop Med Hyg 1958; 7: 334-338.

15. Ayi I, Edu A, Apea-Kubi K, Boamah D, Bosompem K, Edoh D. Seroepidemiology of toxoplasmosis amongst pregnant women in the greater Accra region of Ghana. Ghana Med J 2009; 43:107-114.

16. Terazawa A, Muljono R, Susanto L, Margono SS, Konishi E. High Toxoplasma antibody prevalence among inhabitants in Jakarta, Indonesia. Jpn J Infect Dis 2003; 56:107-109.

17. Jones JL, Parise ME, Fiore AE. Neglected parasitic infections in the United States: toxoplasmosis. Am J Trop Med Hyg 2014; 90:794-749.

18. Hong SJ, Chong CK, Lee K, Kim TS, Hong YP, Ahn HJ, et al. Maintained seroprevalence of toxoplasmosis among the residents of Jeju island, Korea. Korean J Parasitol 2011; 49:309-311.

19. Gebremedhin EZ, Abebe AH, Tessema TS, Tullu KD, Medhin G, Vitale M, et al. Seroepidemiology of Toxoplasma gondii infection in women of child-bearing age in central Ethiopia. BMC Infect Dis 2013; 13:101.

20. Prestes-Carneiro LE, Rubinsky-Elefant G, Ferreira AW, Araujo PR, Troiani C, Zago SC, et al. Seroprevalence of toxoplasmosis, toxocariasis and cysticercosis in a rural settlement, São Paulo State, Brazil. Pathog Glob Health 2013; 107:88-95.

21. Hammond-Aryee K, Esser M, Van Helden PD. Toxoplasma gondii seroprevalence studies on Humans and animals in Africa. S Afr Fam Pract 2014; 56:119-124.

22. Fan CK, Lee LW, Liao CW, Huang YC, Lee YL, Chang YT, et al. Toxoplasma gondii infection: relationship between seroprevalence and risk factors among primary schoolchildren in the capital areas of Democratic Republic of São Tome and Principe, West Africa. Parasit Vectors 2012; 5:141.

23. Dromigny JA, Pecarrere JL, Leroy F, Ollivier G, Boisier P. Prevalence of toxoplasmosis in Tananarive. Study conducted at the Pasteur Institute of Madagascar (PIM) on a sample of 2354 subjects. Bull Soc Pathol Exot 1996; 89:212-216.

24. Ahmed HJ, Mohammed HH, Yusuf MW, Ahmed SF, Huldt G. Human toxoplasmosis in Somalia. Prevalence of Toxoplasma antibodies in a village in the lower Scebelli region and in Mogadishu. Trans Roy Soc Trop Med Hyg 1988; 82:30-32.

25. Jones JL, Kruszon MD, Meadey JB. Toxoplasmosis gondii infection in the USA; seroprevalence and risk factors. Am J Epidemiol 2001; 154:357-365.

26. Nissapatorn V, Azmi Noor MA, Cho SM, Fong MY, Init I, Rohela $\mathrm{M}$, et al. Toxoplasmosis; Prevalence and risk factors. J Obstet Gynaecol 2003; 23:618-624.

27. Simon RF, Adegoke AK, Adewale BA. Slum settlement regeneration in Lagos Mega-city: an overview of a Waterfront Makoko Community. Int J Edu Res 2013; 1:1-16.

28. Fu CJ, Chuang TW, Lin HS, Wu CH, Liu YC, Langinlur MK, et al. Toxoplasma gondii infection: seroprevalence and associated risk 
factors among primary school children in the capital area of the Republic of the Marshall Islands. Jpn J Infect Dis 2014; 67:405-410.

29. Woldemichael T, Fontanet AL, Sahlu T, Gilis H, Messele T, Wit TF, et al. Evaluation of the Eiken latex agglutination test for anti-Toxoplasma antibodies and seroprevalence of Toxoplasma infection among factory workers in Addis Ababa, Ethiopia. Trans Roy Soc Trop Med Hyg 1998; 92:401-403.

30. Swai ES, Schoonman L. Seroprevalence of Toxoplasma gondii infection amongst residents of Tanga district in north-east Tanzania. Tanzan J Health Res 2009; 11:205-209.

31. Stothard JR, French MD, Khamis IS, Basanez MG, Rollinson D. The epidemiology and control of urinary schistosomiasis and soil-transmitted helminthiasis in schoolchildren on Unguja Island, Zanzibar. Trans Roy Soc Trop Med Hyg 2009; 103:1031-1044.

32. Lopes FM, Gonçalves DD, Dos Reis C, Bregano RM, Freire RL, De Freitas C, et al. Presence of domesticated cats and visual impairment associated to Toxoplasma gondii serum positive children at an elementary school in Jataizinho, state of Parana, Brazil. Rev Bra Parasitol Vet 2008; 17:12-15.

33. Meng QF, You HL, Zhou N, Dong W, Wanga WL,Wang WL, et al. Seroprevalence of Toxoplasma gondii antibodies and associated risk factors among children in Shandong and Jilin provinces, China. Int J Infect Dis 2015; 30:33-35.

34. Dattoli VC, Veiga RV, Cunha SS, Pontes-de-Carvalho LC, Barreto ML, Alcantara-Neves NM. Oocyst ingestion as an important transmission route of Toxoplasma gondii in Brazilian urban children. J Parasitol 2011; 97:1080-1084.

35. Jones JL, Lopez B, Alvarez Mury M, Wilson M, Klein R, Luby $\mathrm{S}$, et al. Toxoplasma gondii infection in rural Guatemala children. Am J Trop Med Hyg 2005; 72:295-300.

36. Kamani J, Mani AU, Egwu GO, Kumshe HA. Seroprevalence of human infection with Toxoplasma gondii and the associated risk factors, in Maiduguri, Borno state, Nigeria. Ann Trop Med Parasitol 2009; 103:317-321.
37. Khan I, Khan AM, Ayaz S, Khan S, Anees M, Khan SA, et al. Molecular detection of Toxoplasma gondii in water sources of district Nowshehra, Khyber Pakhtunkhwa, Pakistan. J Toxicol Environ Health 2013; 76: 837-841.

38. Kook J, Lee HJ, Kim BI, Yun CK, Guk SM, Seo M, et al. Toxoplasma gondii antibody titers in sera of children admitted to the Seoul National University Children's Hospital. Korean J Parasitol 1999; 37:27-32.

39. Fan CK, Hung CC, Su KE, Sung FC, Chiou HY, Gil V, et al. Seroprevalence of Toxoplasma gondii infection among preschoolchildren ages 1-5 years in the Democratic Republic of São Tome and Principe, Western Africa. Tran Roy Soc Trop Med Hyg 2006; 100: 446-449.

40. Taylor MRH, Lennon B, Holland CV, Calferkey M. Community study of Toxoplasma antibodies in urban and rural schoolchildren aged 4 to 18 years. Arch Dis Childhood 1997; 77:406-409.

41. Dattoli VC, Veiga RV, Cunha SS, Pontes-de-Carvalho L, Barreto ML, Alcantara-Neves NM. Oocyst ingestion as an important transmission route of Toxoplasma gondii in Brazilian urban children. J Parasitol 2011; 97:1080-1084.

42. Ishaku B, Ajogi I, Umoh J, Lawal I, Randawa A. Seroprevalence and risk factors for Toxoplasma gondii infection among antenatal women in Zaria, Nigeria. Res J Med Sci 2009; 4:483-488.

43. Heukelbach J, Meyer-Cirkel V, Moura RC, Gomide M, Queiroz JA, Saweljew P, et al. Waterborne toxoplasmosis, northeastern Brazil. Emerg Inf Dis 2007; 13:287-289.

44. Prandota J. The importance of Toxoplasma gondii infection in diseases presenting with headaches. Headaches and aseptic meningitis may be manifestations of the Jarisch-Herxheimer reaction. Int J Neurosci 2009; 119: 2144-2182.

45. Jones JL, Holland GN. Annual burden of ocular toxoplasmosis in the US. Am J Trop Med Hyg 2010; 82:464-465.

46. Ambe JP, Gasi IS, Mava Y. Review of neonatal infections in University of Maiduguri Teaching Hospital: common bacterial pathogens seen. Niger J Clin Pract 2007; 10:290-293. 